\title{
A Cloud Based Irrigation System for Agriculture
}

\author{
Sathyanarayanan PSV \# \\ \# IT manager, FORD MOTORS, India \\ E-mail: sathyanarayanaford@gmail.com
}

\begin{abstract}
By 2050, it's normal that the total populace will contact 9.2 billion individuals, 34 percent higher than today. A lot of this development will occur in creating nations like India, which has the biggest zone on the planet with arable land for agriculture. To stay aware of rising populaces and wage development, worldwide sustenance generation must increment by 70 percent so as to have the capacity to encourage the world. With help of IoT, control focuses gather and process information continuously to enable ranchers to settle on the best choices as to planting, treating and collecting crops. Sensors set all through the fields are utilized to gauge temperature and stickiness of the dirt and encompassing air. We Propose a Cloud based Irrigation System for better agriculture farming.
\end{abstract}

Keywords - Cloud Computing, Smart Agriculture, Sensors, Internet of Things(IoT).

\section{INTRODUCTION}

Horticulture assumes the critical part in the economy and improvement of the nation like India. In our nation, the ranchers have been utilizing manual control methods for water system. Land is flooded just at the general interims/seasons. In this procedure, few plants in the zone get more water and for couple of other zone plants water achieves late because of which the crops get dried.

There is a need in the private/business water system industry for a water system controller that reacts to soil dampness sensors in singular zones as a method for preserving water. A perfect controller ought to be "easy to use", i.e., simple to program and requiring a base number of keys or push-catches to work the controller. It ought to likewise permit water system to happen in zones where watering is required, while bypassing zones where sufficient soil dampness is demonstrated.

To include adaptability, it ought to be conceivable to specifically deactivate any of the dampness sensors to in this way supersede the alteration to the controller Performance caused by sensor inputs. The pesticide sprinkling instruments in this framework splashes the pesticide blend in the proportion merited by the plants. In addition, the framework ought to be anything but difficult to investigate in the occasion of deficiencies in any of the majority of zones.

\section{RECENT WORKS}

Water system might be characterized as the art of simulated utilization of water to the land or soil. It is utilized to aid the developing of rural products, support of scenes, and revegetation of irritated soils in dry zones and amid times of lacking precipitation. Moreover, water system likewise has a couple of different uses in trim generation, which incorporate securing plants against ice, stifling weed developing in grain fields and aiding in forestalling soil combination. In differentiate, horticulture that depends just on coordinate precipitation is alluded to as rain-nourished or dry-arrive cultivating. Water system is frequently examined together with seepage, which is the normal or fake expulsion of surface and sub-surface water from guaranteed region. G. K. Banerjee and Rahul Singhal [1] proposed a technique utilizing microcontroller for the control of temperature and relative stickiness inside a poly house. In the proposed technique, the nursery controller detects the adjustment in temperature and relative stickiness with the assistance of info sensors and process the yield to make suitable control move. The proposed framework is a minimal effort and easy to understand framework with high strength and dependability.

\section{Cloud Centre Based Framework}

Customarily agribusiness is polished by playing out a specific assignment, for example, planting or collecting, against a foreordained timetable. Be that as it may, by gathering ongoing information on climate, soil and air quality, edit development and even gear and work expenses and accessibility, prescient investigation can be utilized to settle on more quick witted choices. This is known as accuracy farming. With exactness horticulture, control focuses gather and process information progressively to enable agriculturists to settle on the best choices as to planting, treating and 
collecting crops. Sensors set all through the fields are utilized to gauge temperature and dampness of the dirt and encompassing air. Also, pictures of fields are taken utilizing satellite symbolism and automated automatons. The pictures after some time demonstrate trim development and when combined with prescient climate displaying indicating pinpoint conditions 48 hours ahead of time.

Keeping in mind the end goal to develop edits ideally agriculturists need to see how to develop those harvests in a specific region, considering a seed's imperviousness to climate and nearby maladies, and considering the natural effect of planting that seed. For instance, when planting in a field close to a waterway, it's best to utilize a seed that needs less manure to support lessen contamination.

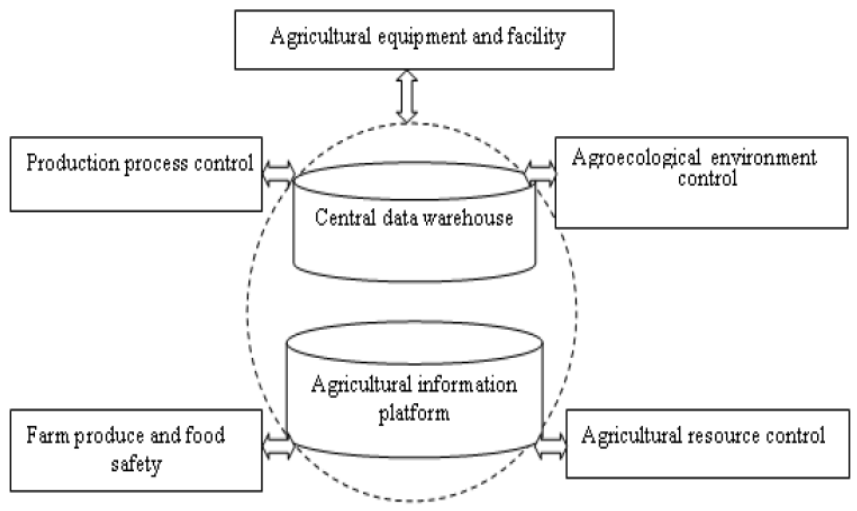

Fig 1. Smart Agriculture system based on IoT
Once the seeds have been planted, the choices made around treating and keeping up the yields are time-delicate and intensely impacted by the climate. On the off chance that agriculturists know they'll have substantial rain the following day, they may choose not to put down compost since it would escape. Knowing whether it will rain or not can likewise impact when to inundate fields. With 70 percent of crisp water overall utilized for agribusiness, having the capacity to better oversee how it's utilized will hugy affect the world's new water supply.

Climate influences how crops develop, as well as coordinations around gathering and transportation. When collecting sugar stick, for instance, the dirt should be sufficiently dry to help the heaviness of the reaping gear. On the off chance that it's damp and the dirt is wet, the hardware can crush the product. By understanding what the climate will be more than a few days and what fields will be influenced, better choices can be made ahead of time about which fields specialists ought to be conveyed to.

Once the sustenance has been gathered the coordinations of collecting and transporting nourishment to the appropriation focuses is vital. A considerable measure of nourishment squander occurs amid conveyance, so it's essential to transport the sustenance at the correct temperature and not hold it for longer than required. Indeed, even the climate can influence this; in India, a considerable lot of the streets are soil, and overwhelming precipitation can make trucks stall out in mud. By knowing where it will rain and which courses might be influenced, organizations can settle on better choices on which courses will be the quickest to transport their nourishment

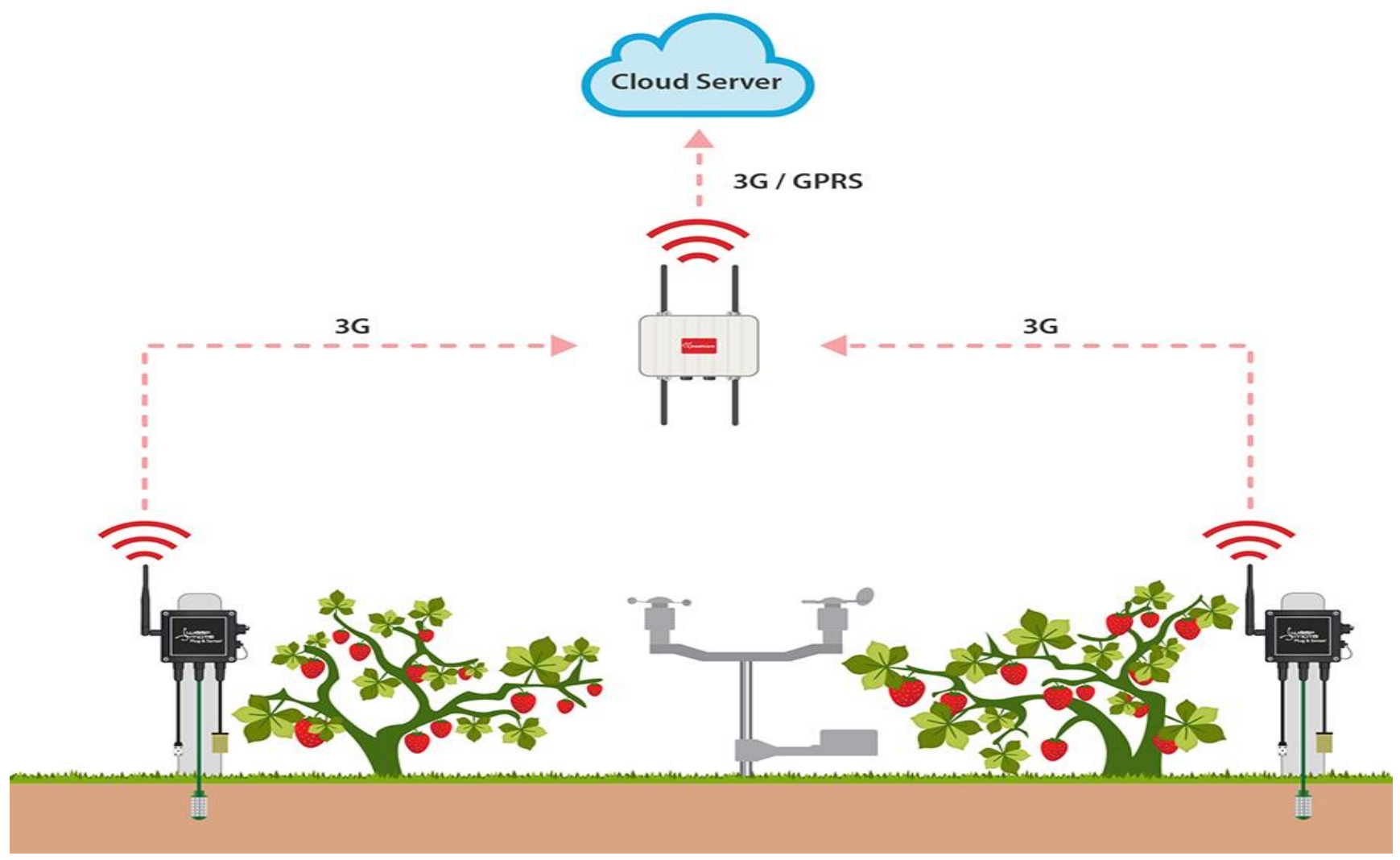

Fig 2. A cloud control center for Data collection from the Fields 


\section{CONCLUSIONS}

At present, exactness farming advances are utilized by bigger organizations as it requires a strong IT foundation and assets to do the checking. Be that as it may, Ulisses imagines a day when littler homesteads and communities could utilize cell phones and group sourcing to upgrade their own farming. An agriculturist could take a photo of a yield with his telephone and transfer it to a database where a specialist could evaluate the development of the product in light of its shading and different properties. Individuals could give their own particular perusing on temperature and dampness and be a substitute for sensor information if none is accessible.

With developing requests on the world's nourishment production network, it's essential to expand farming assets in a reasonable way. With aptitude in superior supercomputing, computational sciences, and investigation and enhancement,
Research is exceptionally ready to comprehend the complexities of horticulture and build up the correct climate estimates, models and reproductions that empower ranchers and organizations to settle on the correct choices.

\section{REFERENCES}

[1] G K Banerjee, Rahul Singhal, "Microcontroller Based Polyhouse Automation Controller", ISED '10 Proceedings of 2010 International Symposium on Electronic System Design.

[2] Muhammad Ali Mazidi and Janice Gillispe Mazidi, "The 8051 microcontroller and embedded systems", Pearson education ltd. India, 2007.

[3] A.Phocaides, FAO Consultant "Technical handbook on Pressurized Irrigation Techniques"

[4] Masayu Binti Hussein "Automatic Greenhouse Watering System using Microcontroller."

[5] N. Dinesh Kumar, S. Pramod And Ch Sravani ," Intelligent Irrigation System", International Journal of Agricultural Scienceand Research (IJASR), Vol. 3 Issue 3, Aug 2013, 23-30. 